\title{
An Investigation on the Formation and Development of Non-English Major' English Mental Lexicon
}

\author{
Wei $Y^{1,2}$ \\ ${ }^{1}$ Wuhan University, Wuhan , 430072, China \\ ${ }^{2}$ Foreign Language School, Wuhan University of Technology, Wuhan, 430070, China \\ email: yaoweivivian@qq.com
}

Keywords: Chinese EFL learners; mental lexicon; LCCM theory; usage-based theory of language acquisition; theory of personal experience

\begin{abstract}
EFL learning and teaching, and the necessity to carry out explorations into Chinese EFL learners' English mental lexicon. It aims to find out the formational and developmental features of Chinese EFL learners' English mental lexicon as well as the factors that influence the formation and development of the mental lexicon. Based on the findings of the present study, suggestions for EFL vocabulary learning and teaching and recommendations for future studies are put forward.
\end{abstract}

\section{Introduction}

In the study of bilingual mental lexicon, there are researchers who believe that the organization of the L2 mental lexicon is different from that of the LI. On the basis of the literature review, it goes on to construct the theoretical framework for the present study, which includes: LCCM Theory (the Theory of Lexical Concepts and Cognitive Models) (Evans, 2006, 2009) [1], the Usage-Based Theory of Language Acquisition (Langacker, 1987, 1991; Tomasello, 2003) and the Theory of Personal Experience (Dai, 2007). [2]With the theoretical framework serving as the guideline, the word test and the questionnaire are designed to examine the formation and development of Chinese EFL learners' English mental lexicon at three different developmental stages. The most comprehensive evidence supporting this view is provided by Paul Meara [3] (1978; 1980; 1982; 1984). Meara established and directed the Birkbeck Vocabulary Project in the 1980s and by analyzing the results of learner responses to a series of word association tests from the project, he claimed that "there are good reasons for believing that there might be significant differences between the lexicon of a learner and that of a native speaker" (Meara, 1984:231). [4]Besides studies on the organization of the L2 mental lexicon, there are many researches carried out to examine the semantic processing in bilingual speakers. In China, scholars have also carried out quite a number of theoretical and empirical studies on bilingual mental lexicon. The following part begins with the Shared (Distributed) Asymmetrical Model (SAM) (Figure 2-7) proposed by Dong, Gui and MacWhinney (2005) [5] and ends with an overview of some empirical studies on bilingual mental lexicon carried out in China. These studies are of significance as they have provided some useful and insightful exploration into bilingual mental lexicon. The present study tries to establish a tentative theoretical framework of L2 mental lexicon based on LCCM theory, the theory of personal experience and the usage-based theory of language acquisition. With this proposed theoretical framework functioning as the guideline, a word test and a questionnaire will be designed and employed as the instrument to carry out exploration into Chinese EFL learners' English mental lexicon. 


\section{Methodology}

A. Research Questions

a. What does the English mental lexicon of Chinese English learners look like? To be more specific, what units of word knowledge are represented in the mental lexicon of Chinese EFL learners?

b. How does the mental lexicon of Chinese EFL learners develop? What are the developmental features of Chinese English learners’ English mental lexicon?

B. Research Design

With word knowledge test, this study tries to find out the formational features of Chinese English learners' mental lexicon, or in other words, what units of word knowledge are stored in Chinese English learners’ English mental lexicon.

C. Subjects

400 students were randomly chosen from Wuhan University. All of the subjects have Chinese as their native language and English as their foreign language. None of them had ever lived in an English speaking country.

D. Questionnaire

The questionnaire is divided into two parts. The purpose of the first part is to investigate the learning habits of Chinese EFL learners, and that of the second part is to explore the teaching habits of Chinese EFL teachers. Students are asked to read the short paragraph which is followed by fifteen statements. In the second part, there are altogether eight statements. Students are asked to read the eight statements and then decide whether each statement is consistent with the teaching habits of his or her English teachers.

E. Data Collection

The data were collected between October $25^{\text {th }}$ and November $10^{\text {th }}$ during that period, the word knowledge tests and questionnaires were distributed to English teachers or students in the statistical analysis software SPSS (17.0) is employed to analyze the data.

\section{Result and discussion}

A. Subjects' performance in the word meaning test

Table 1 The performance of subjects in the word meaning test: uncle

\begin{tabular}{|c|c|c|c|c|c|c|c|}
\hline & category & \multicolumn{2}{|c|}{ freshmen } & \multicolumn{2}{c|}{ sophomores } & \multicolumn{2}{c|}{ juniors and seniors } \\
\hline \multirow{3}{*}{ Valid } & & Frequency & Percent & Frequency & Percent & Frequency & Percent \\
\cline { 2 - 8 } & $\mathrm{A}$ & 19 & 16.1 & 14 & 14.0 & 10 & 11.1 \\
\cline { 2 - 8 } & $\mathrm{B}$ & 11 & 9.3 & 17 & 17.0 & 7 & 7.8 \\
\cline { 2 - 8 } & $\mathrm{C}$ & 15 & 12.7 & 7 & 7.0 & 8 & 8.9 \\
\cline { 2 - 8 } & $\mathrm{D}$ & 40 & 33.9 & 34 & 34.0 & 44 & 48.9 \\
\cline { 2 - 8 } & E & 33 & 28.0 & 28 & 28.0 & 21 & 23.3 \\
\cline { 2 - 8 } & Total & 118 & 100.0 & 100 & 100.0 & 90 & 100.0 \\
\hline
\end{tabular}

Table 1 shows the performance of subjects in word meaning test: uncle. As is shown in table 1 , the meaning of uncle stored in Chinese EFL learners' English mental lexicon is incomplete, or in other words, there are still a large number of students who do not know the complete meaning of the English word uncle even though they have leant the word for at least six years. 
Table 2 The performance of subjects in the word meaning test: beautiful

\begin{tabular}{|c|c|c|c|c|c|c|c|}
\hline & category & \multicolumn{2}{|c|}{ freshmen } & \multicolumn{2}{c|}{ sophomores } & \multicolumn{2}{c|}{ juniors and seniors } \\
\hline \multirow{3}{*}{ Valid } & & Frequency & Percent & Frequency & Percent & Frequency & Percent \\
\cline { 2 - 8 } & A & 20 & 16.9 & 9 & 9.0 & 8 & 8.9 \\
\cline { 2 - 8 } & B & 19 & 16.1 & 15 & 15.0 & 12 & 13.3 \\
\hline C & 15 & 12.7 & 16 & 16.0 & 14 & 15.6 \\
\hline D & 13 & 11.0 & 11 & 11.0 & 18 & 20.0 \\
\hline E & 51 & 43.2 & 49 & 49.0 & 38 & 42.2 \\
\hline & Total & 118 & 100.0 & 100 & 100.0 & 90 & 100.0 \\
\hline
\end{tabular}

Table 2 summarizes the performance of subjects in the word meaning test: beautiful. As is shown in the table, for more than $50 \%$ of the subjects, the meaning stored in Chinese EFL learners' English mental lexicon is incomplete. For some students (about 10\%), beautiful is just related to the visual sense, and the meaning stored in their mental lexicon is the Chinese equivalent meilide (that can give pleasure to the visual sense) though beautiful can be used to describe anything that can give pleasure to all the five senses.

B. Subjects' performance in the word syntax test

Table 3 The performance of subjects in the word syntax test: save

\begin{tabular}{|c|c|c|c|c|c|c|c|}
\hline & category & \multicolumn{2}{|c|}{ freshmen } & \multicolumn{2}{c|}{ sophomores } & juniors and seniors \\
\hline \multirow{3}{*}{ Valid } & & Frequency & Percent & Frequency & Percent & Frequency & Percent \\
\cline { 2 - 8 } & 0 & 40 & 33.9 & 28 & 28.0 & 33 & 36.7 \\
\cline { 2 - 8 } & 1 & 36 & 30.5 & 34 & 34.0 & 18 & 20.0 \\
\cline { 2 - 8 } & 2 & 33 & 28.0 & 32 & 32.0 & 29 & 32.2 \\
\cline { 2 - 8 } & 3 & 9 & 7.6 & 6 & 6.0 & 10 & 11.1 \\
\hline & Total & 118 & 100.0 & 100 & 100.0 & 90 & 100.0 \\
\hline
\end{tabular}

Table 3 reports the performance the subjects in word syntax tests. As is shown in the table, at every developmental stage, there are about 30\% students who do not know any word syntax of "save" at all. Among those who know word syntax to some degree, those who can write down three structures account for only a small proportion, $7.6 \%$ for freshmen, $6 \%$ for sophomores and $11.1 \%$ for juniors and seniors. Though compared with the freshmen and sophomores, more juniors and seniors do not write down any word structure at all, the percentage of juniors and seniors who can write down two or three word structures is greater than that of the freshmen and sophomores.

C. Results of the Questionnaire

Word form learning;

$43.55 \%$ of the subjects express that they will not write down the phonetic symbols when looking up a new word in the dictionaries even if they do not know how to pronounce the word correctly. That confirms the results of question 1 in the word knowledge test and that also explains, to some extent, why students have difficulty in distinguishing between different word forms, both phonological forms and written forms.

Word meaning learning: when encountering a new English word in reading, $51.61 \%$ of the subjects say that they will look it up in the dictionaries and then write down and memorize the Chinese meaning of the word. $79.03 \%$ of the subjects say the dictionaries they use are English to Chinese ones. Even though there are English definitions on the dictionaries, 51.61\% of the subjects say they do not read the English definitions.

Word syntax learning: 50\% of the subjects express that they have already noticed the importance of word syntax in English vocabulary learning and they will pay attention to the word syntax learnt in classes. However, in the interviews with some students, they admit that in vocabulary learning after class, what they value most and pay most attention to is the vocabulary size.

D. Discussion of the Results of Data Analysis

The situation of different aspects of word knowledge stored in Chinese EFL learners' English 
mental lexicon is like this; many students still have difficulty in distinguishing between similar words forms (both phonological forms and written forms). A dose examination of students' responses reveals that it is more difficult for them to distinguish between different phonological forms. As far as word context is concerned, the majority of students can recognize the meaning.

The comparison between performances of students at different developmental stages reveals that as the language proficiency level of Chinese EFL learners improves, knowledge of different aspects of word knowledge also increases. To be more specific, knowledge of word form, word meaning, word collocation, word syntax and word context increases as language proficiency improves.

As language is usage-based in nature, it is in experiencing language use in different situations and different social contexts that one learns how to use the language in an appropriate way. However, as Chinese EFL learners, students learn English in Chinese context. For them, there is no sufficient contextualized English input, and results of the questionnaire and interviews indicate that most students are learning the English language passively. According to LCCM theory, lexical concepts is the semantic element that is paired with a unique phonological vehicle in a symbolic unit, while cognitive model is a large-scale coherent body of non-linguistic knowledge which lexical concepts provide access site to. Another point that is worth mentioning is that when Chinese EFL learners begin to learn English, they have already formed a strong relationship between Chinese word form and word meaning, and that word meaning is related to word use.

\section{Conclusions}

Chinese EFL learners display a very weak acquisition of word knowledge in their English mental lexicon. Of the eight aspects of word knowledge in the mental lexicon, the ones that are stored in the mental lexicon of Chinese EFL learners are word form (phonological form and written form) and word meaning. For quite a number of words, the phonological forms are lost in the mental lexicon, and the meanings stored are just LI equivalent translation. The factors that may influence the formation and development of Chinese EFL learners' English mental lexicon include: Chinese lexical system, Lack of sufficient contextualized L2 input, Lack of awareness of L2 role recognition. The strategies that most teachers employ in then classroom setting, paraphrasing and guessing meaning from the context stress the skill of finding a similar meaning or giving a brief definition of the target word. The ultimate aim of this study on Chinese EFL learners' English mental lexicon is to shed light on L2 vocabulary acquisition. Also, it attempts to provide some practical implications for L2 vocabulary teaching.

\section{Acknowledgement}

This research was financially supported by Fundamental Research Funds for the Central Universities (Grant NO. 2015-VI-042).

\section{References}

[1] Kana Okano, Jonathan Grainger, Phillip J. Holcomb. An ERP investigation of visual word recognition in syllabary scripts[J]. Cognitive, Affective, \& Behavioral Neuroscience . 2013 (2)

[2] Jeffrey D. Johnson, Susan G.R. McDuff, Michael D. Rugg, Kenneth A. Norman. Recollection, Familiarity, and Cortical Reinstatement: A Multivoxel Pattern Analysis [J]. Neuron . 2009 (5)

[3] Shidrokh Namei. Bilingual lexical development: a Persian-Swedish word association study[J]. International Journal of Applied Linguistics . 2004 (3)

[4] Henriksen, B. Declarative lexical knowledge. Vocabulary and Writing in a First and Second Language: Processes and Development . 2008

[5] David D. Qian, Mary Schedl. Evaluation of an in-depth vocabulary knowledge measure for assessing reading performance. Language Testing. 2004 